Article

\title{
Airworthiness and Conceptual Design Optimization Considerations of the Environmental Impact Assessment of a Supersonic Business Jet Aircraft
}

\author{
Ilias Lappas $1, *,+$, Nikolaos Pergamalis ${ }^{2,+}$ \\ 1 Department of Mechanical and Aeronautical Engineering, School of Engineering, \\ University of South Wales, Treforest Campus, Treforest CF37 1DL, UK \\ 2 State Aircraft Depot, Hellenic Air Force, Elefsis Air Force Base 19200, Elefsis, Greece; \\ nikolaos.pergamalis@haf.gr \\ * Correspondence: ilias.lappas@southwales.ac.uk; Tel.: +44-01443-482565 \\ + These authors contributed equally to this work.
}

\begin{abstract}
In recent years, the anticipation of sustainable supersonic passenger jet operations has elevated again. The progress achieved in propulsion together with the increased usage of composite materials favour the potential of sustained and cost efficient supersonic commercial operations. However, obstacles remain with regards to the certification of the new supersonic aircraft platforms, while the two main certification bodies EASA and FAA are under pressure to develop certification requirements which will reassure that the supersonic operations are going to have the least possible environmental impact. From a design perspective, past and current research suggests that there is a trade-off between the aircraft performance and the environmental impact, which should be balanced. The current study attempts to balance this trade-off and to conceptually design a SuperSonic Business Jet (SSBJ) by taking into account environmental concerns of the supersonic flight together with design methods that facilitate a sustained supersonic cruise. An environmental impact assessment is undertaken for the SSBJ design and its results are compared to a typical commercial subsonic airliner.
\end{abstract}

Keywords: supersonic business jet; SSBJ; environmental impact assessment; supersonic flight; airworthiness; aircraft certification.

\section{Acronyms}

AR

CFD

FAA

HSR

ISA

MAC

MTOW

MZFW
Aspect Ratio

Computational Fluid Dynamics

Federal Aviation Administration

High Speed Research

International Standard Atmosphere

Mean Aerodynamic Chord

Maximum Take Off Weight

Maximum Zero Fuel Weight 


$\begin{array}{ll}\text { NACA } & \text { National Advisory Committee for Aeronautics } \\ \text { NASA } & \text { National Aeronautics and Space Administration } \\ \text { QueSST } & \text { Quiet Supersonic Technology } \\ \text { SSBJ } & \text { Super Sonic Business Jet }\end{array}$

\section{Introduction}

In recent years, the prospect for a supersonic passenger jet operation has risen again. The progress achieved in jet propulsion engines and the possibility of composite materials usage at the aircraft structure are the main reasons that the success of the supersonic flight has become much more feasible nowadays compared to the past. NASA has already began to work on the preliminary design for a low-boom supersonic passenger with the project Quiet Supersonic Technology (QueSST) which has focused its interest in the supersonic transportation, after the High Speed Research (HSR) program that phased out in 1999. Moreover, a newly founded company, named Boom Technology Inc., has progressed the development of a supersonic transport aircraft being able to fly at a speed of $2.2 \mathrm{Mach}$ and carry up to 45 passengers [1].

Apart from the economic feasibility for the supersonic passenger jet success, the environmental restrictions and impact are important factors as well. The overland flight ban, which has been implemented due to the sonic boom, and the increased air pollutants emissions have been primary concerns which affect the certification process and the mission requirements. At the present study, an effort is made for a supersonic transport aircraft conceptual design, which could be viable in the current and future market. The conceptual design process and its validation are demonstrated and an environment impact assessment of the design is undertaken.

Flying supersonic has always been a very promising and tempting idea. A flight duration could become two or three times less in comparison to the subsonic flights. After the Concorde's retirement in 2003, the supersonic civil transportation is not existent any more. Although the required technology to construct supersonic aircraft exists, the economic sustainment of the concept is still a very challenging task [2]. The supersonic overland flight ban has also imposed one more important constraint. For the above reasons, an excessive turn of the civil transportation from subsonic to supersonic is highly improbable at least in the upcoming decade. However, the need for long-haul flights is expected to increase significantly during the next twenty years. According to the Airbus [3] forecast for the global market for the period from 2016 to 2035, an increase of $95 \%$ is anticipated for the long-haul traffic. This sets a quite promising ground for the prospects of the supersonic flight, where its biggest advantage of diminishing the flight time could be maximally exploited. Small supersonic airliners carrying about 15 to 25 passengers could allow the economic success of the concept, since the development risk and expenditure will be significantly lower, while having a promising market share [4]. Private individuals who are keen to buy business jets could be potential customers for small supersonic aircraft too. Other potential customers could be government agencies, since officials could save valuable time, and big corporations. Regarding the overland ban, the solution of planning routes that cover long overseas distances seems the most realistic. The 
possibilities given for mostly overseas long-haul flights decreases the necessity for an extreme lowboom design.

Having reviewed additional studies $[5,6,7,8,9]$, there is a consensus that the most feasible supersonic transport design, considering primarily the financial and not the technical aspects, would be the production of a small supersonic business jet aircraft (SuperSonic Business Jet-SSBJ from now on), that could carry 15 passengers and have a range of about $7200 \mathrm{~km}$. A small size supersonic aircraft is considered to be an attractive choice for frequent business travellers and for a portion of business jet users, which together make a potential 10\% market share [10]. The cruise speed would be 1.7 Mach, which is about double of the regular cruise speed of a subsonic airliner. Although a higher Mach number would have been more enticing for the clients, the choice of a moderate speed would result in designing an aircraft with reduced weight, having a positive effect in fuel consumption and noise generation [11]. In general, a combination of lower speeds and cruise altitudes facilitates the mitigation of aviation related global warming [12]. Several studies [12, 13, 14, 15] have attempted to assess the aviation climate impact and how this might influence the aircraft design criteria of typical generic or existing subsonic airliners and the novelty of the present study is that it attempts to perform an environmental assessment comparison and to look at aircraft design criteria implications of a particular SSBJ design.

\section{Methodology}

The environmental concerns of the supersonic flight together with design methods that facilitate a sustained supersonic cruise are introduced at the following paragraphs. Based on those concerns and design methods, the conceptual design of the SSBJ is going to be undertaken, resulting in a model which will be used to estimate its potential environmental impact.

\subsection{Sonic boom}

One of the most important environmental concerns of the SSBJ operation is the aerodynamic noise generated by the shock waves [16]. NASA is conducting research in this field in order to create a low boom design, which could be quiet enough to overcome the applied restrictions. The early sonic boom research was conducted according to modified linear methods, based on Whitham's theory for the sonic boom prediction [17], [18]. According to the linear theory, the pressure signatures reaching the ground are $\mathrm{N}$-waves, which are typical for aircraft with high wing loading. However, later work has shown that generation of non-N-waves on the ground was possible [19]. Moreover, some important deficiencies have been recognized regarding the linear methods, which made necessary the development of more accurate methods and their experimental validation through flight testing. Therefore, the later studies focused on creating aircraft concepts with lift and volume distributions that would shape non-N-waveforms at the ground, rather than trying to reduce the noise generated by the $\mathrm{N}$-waves, which created substantial limitations.

Haglund [20] has examined several concepts based on a reference design. The delta baseline wing has been changed into a wing arrow design, having about the same aerodynamic efficiency. It has been found that a bigger wing is beneficial since the lower wing loading results in reduced pressure levels to sonic boom for the lift contribution. However, this sonic boom loudness reduction comes with a significant price, which is an increase of about $12 \%$ on the Maximum Take Off Weight (MTOW) per passenger. Thus, it has become clear that the low boom design is related with a performance penalty, as an effect of the increased aircraft structural weight. Moreover, the high wing sweep, in 
addition to the low aspect ratio, makes the low speed performance of the aircraft very challenging. The above observations suggest that there is a trade-off between the aircraft performance and the sonic boom loudness, which has to be balanced [21].

Furthermore, the low boom design usually leads to the aircraft wave drag increment. The sonic boom minimization concepts adopt blunt nose, which is far from the optimal configuration for minimal wave drag. A blunt nose creates a strong bow shock, so that the secondary shocks are weak and do not overtake and enhance the front shock. This way, the produced far field pressure signature becomes much weaker than in the case of a sharp nose, where the front bow shock coalesces with the stronger secondary shock waves [22]. In this case, the nose shape is a trade-off between the sonic boom loudness and the wave drag magnitude as well.

The examination of low boom concepts for aircraft with high payload has shown that it was very difficult to achieve theoretical ground overpressure substantially less than 1 psf [23]. For that reason, a lighter and smaller aircraft would be perhaps a better candidate for decreasing the sonic boom loudness. A lighter aircraft demands less lift to sustain level flight, which is a factor that decreases the sonic boom intensity [24]. For shaped pressure signatures, work of Shepherd and Sullivan [25] provides a method to obtain the relevant perceived level of noise loudness.

The wing planform is an important factor for achieving reduced sonic boom. In the case of a small SSBJ design, still reduced wing loading is needed and thus a large wing. It is important too that the wing incorporates a long wing root, which will result in the gradual development of the area and lift. Moreover, the span cannot be decreased too much, in order to maintain an acceptable performance during the low-speed flight. Normally, the wing in a low boom design is usually placed well aft in comparison with the conventional one, so that its interaction with the aircraft nose shock is reduced. However, this creates serious problems with the aircraft stability. The center of gravity of the fuel placed in the wing can be at a long distance with respect to the empty aircraft center of gravity, which can result in large shifts of the center of gravity location [26]. For that reason, as much fuel as possible should be placed in the front portion of the wing, which due to its increased size and thus volume, will perhaps offer this opportunity. Finally, this will place a constraint on how much thin airfoils should be used to achieve the desired volume for the fuel storage, which would subsequently influence the drag.

The fuselage design of a SSBJ design has also the disadvantage of the decreased fineness ratio, since the length of the body is smaller, but the maximum diameter cannot be decreased too much in order to be able to house the passengers and the systems of the aircraft. That causes an important wave drag penalty on the design. Furthermore, the optimal position of the engines would be the aft fuselage behind the wing trailing edge [23]. This wing-nacelle interference would be avoided and the flow field disturbances of the nacelles would correspond just to the volume and not to the lift contribution effects. Another advantage would be the increased space for the trailing edge devices placement on the wing. However, the engines support in this location would add on structural weight as well.

\subsection{Enviromental concerns of the supersonic flight}

The major environmental effects of aviation include primarily the climate change and the ozone layer depletion. The two more prominent operational differences between supersonic and subsonic 
cruise are the increased fuel consumption, which leads to an increase in combustion products, and the higher cruise altitude of the supersonic compared to the subsonic aircraft.

The climate change, which is particularly being referred as enhanced greenhouse effect or global warming, is one of the most important environmental concerns. The uniqueness of the aircraft operation, compared to the other human activities affecting the climate change, is the direct emission of air pollutants into the higher levels of the atmosphere. The gases, which are being emitted from the jet engines and contribute to the greenhouse effect, are the carbon dioxide, the nitrogen oxides and the water vapor. The greenhouse effect increases the temperature of the Earth by trapping heat in the atmosphere. This heat is a result of the sun radiation absorption from the greenhouse gases, which are hindering the heat absorbed from the ground to bounce back to space. The global average surface temperature of the earth has increased by $0.6{ }^{\circ} \mathrm{C}$ during the 20th century, while a increment of at least $1.8^{\circ} \mathrm{C}$ is expected for the next one [27]. Apart from the global temperature rise, this trapping of heat in the atmosphere can also affect the weather conditions on the planet, such as the appearance of heavier rainfall, floods, tornadoes, thunderstorms. Investigations have also shown that the oceans are possible to expand, the ice on the poles to melt and the surface of the sea level to rise covering parts of the existing land.

Although the contribution of the aviation emissions is only a small portion of the total greenhouse gases emissions, the increment of the air traffic over the last years and the forecast for the upcoming ones, show that can develop in a rather serious factor of the climate change. According to the European Environmental Agency [28], the emissions of $\mathrm{CO}_{2}$ have increased about $80 \%$ between 1990 and 2014, while the prediction is for a further growth of $45 \%$ between 2014 and 2035. There are currently no requirements for the engine certification with respect to the greenhouse gases. However, the recent trend of the aviation emissions increment, make their influence on the enhanced greenhouse effect more critical.

From the emitted gases the most problematic for the greenhouse effect is considered to be the $\mathrm{CO}_{2}$, which among else has a long life cycle. The $\mathrm{H}_{2} \mathrm{O}$ can be considered a significant emission too, especially for flying vehicles in the stratosphere, like the supersonic transport. Flying in such high altitudes, with very low temperatures, the water vapor produced is converted into persistent contrails, which evaporate very slowly. These contrails may be very long (dozens of kilometers), forming the so-called cirrus cloud fields, which can potentially have a strong influence in the climate change. The water is produced as a fixed ratio to fuel which is consumed for complete combustion of kerosene, like in the case of the carbon dioxide. In particular, the combustion of $1 \mathrm{Kg}$ kerosene produces 3.16 $\mathrm{Kg} \mathrm{CO}_{2}$ and $1.24 \mathrm{Kg} \mathrm{H}_{2} \mathrm{O}$ [29].

\subsection{Conceptual design of the SSBJ aircraft model.}

Having discussed the environmental concerns of the supersonic flight and some of the design methods which facilitate a sustained supersonic cruise, the present section will look at the conceptual design of a commercial solution for a SSBJ model. The aircraft model parameters will be used at the next section to estimate its potential environmental impact.

\subsubsection{Initial sizing}

The desired requirements for the SSBJ of the study are presented at the Table 1. 
Table 1. Summary of the desired SSBJ requirements.

\begin{tabular}{cc}
\hline Parameter (unit) & Value \\
\hline Cruise speed Mach number & 1.7 \\
Minimum payload mass $(\mathrm{Kg})$ & 1900 \\
Cruise altitude $(\mathrm{ft})$ & 49000 \\
Range $(\mathrm{Km})$ & 7200 \\
Loiter time $(\mathrm{min})$ & 20 \\
Landing distance $(\mathrm{m})$ & 3500 \\
Take off distance at ISA, Sea level (m) & 3500 \\
Thrust specific fuel consumption at & 26.9 \\
cruise condition (g/KNs) & 3.2 \\
Aspect Ratio-AR &
\end{tabular}

The payload corresponds to 15 passengers plus the pilot, the co-pilot and two crew members. An average of $100 \mathrm{~kg}$ is assigned for each person on-board including the luggage. A low AR value of 3.2 has been selected, since a long wing would have resulted in larger values of the wave drag. The weight fractions and the maximum lift-to-drag ratio for the most efficient cruise have been calculated assuming a typical mission profile for a transport aircraft (Taxi, Warm Up $\rightarrow$ Take off $\rightarrow$ Climb $\rightarrow$ Cruise $\rightarrow$ Loiter $\rightarrow$ Descend $\rightarrow$ Landing and Taxi).

To calculate the required fuel for the mission of the aircraft, the methodology followed by Mariens [30] and introduced by Roskam [31] has been used. This methodology uses a combination of the classic Breguet performance theory, together with statistical factors that estimate the fuel weight of the typical segments of the aircraft's mission. The statistical factors are shown at the Table 2.

Table 2. Fuel fraction for each segment of a typical flight mission, as suggested by Roskam [31] .

\begin{tabular}{cc}
\hline Fuel weight fraction $\left(\mathbf{M}_{\mathrm{ffi}}\right)$ & $\begin{array}{c}\text { Turbojet } \\
\text { aircraft }\end{array}$ \\
\hline Start and warm up & 0.990 \\
Taxi & 0.990 \\
Take off & 0.995 \\
Climb & 0.980 \\
Cruise & Calculated \\
Descent & 0.990 \\
Landing, taxi and shutdown & 0.992 \\
\end{tabular}

Each fuel weight fraction $M_{f f i}$ is the ratio of the total aircraft weight at the end of the flight segment to the total aircraft weight at the beginning of the segment. Thus, the total fuel weight fraction defines the consumed fuel as a ratio of the total aircraft weight at the end of the flight mission to the total aircraft weight at the beginning. The total fuel weight fraction is also equal to the product of all the fuel weight fractions, thus the following equation applies:

$$
\mathrm{M}_{f f}=\prod_{i=1}^{n} M_{f f i}=1-\frac{W_{\text {fuel }}}{W_{\text {take off }}}
$$


Using empirical relations from Raymer [32], the wing loading W/S and the thrust to weight ratio T/W can be estimated, which allow us to estimate the MTOW and the Maximum Zero Fuel Weight

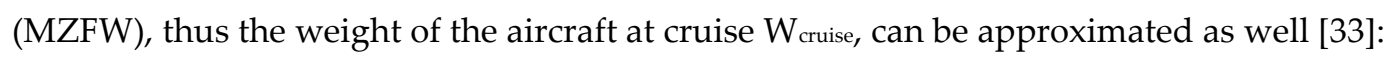

$$
W_{\text {cruise }}=\sqrt{(M T O W) x(M Z F W)}
$$

The results obtained from the initial sizing analysis are presented at the Table 3 below.

Table 3. Summary of initial sizing analysis results

\begin{tabular}{cc}
\hline Parameter (unit) & Value \\
\hline Empty weight fraction & 0.472 \\
Fuel weight fraction & 0.464 \\
Take off mass $(\mathrm{Kg})$ & 29500 \\
Wing loading at take off $\left(\mathrm{N} / \mathrm{m}^{2}\right)$ & 5110 \\
Wing loading at stall $\left(\mathrm{N} / \mathrm{m}^{2}\right)$ & 4539 \\
Maximum thrust to weight ratio & 0.585 \\
Take off distance at ISA, Sea level (m) & 2283 \\
\hline
\end{tabular}

\subsubsection{Wing}

A trapezoidal shaped wing with a NACA 64-006 aerofoil and a leading edge wing sweep of 45 degrees has been selected for the SSBJ configuration, so that the wing is capable of creating the necessary lift to satisfy the takeoff and landing distance requirements. The use of a swept wing endorses a highly tapered wing in order to preserve the desired elliptical lift contribution over the wing, which in turn reduces the lift induced drag. However, a very low taper ratio has the consequence of tip stalling tendency. Moreover, it can be limited by restrictions concerning adequate chord near wing tips for the ailerons placement. Recommended values for highly swept wings in supersonic flow are 0.2 - 0.3 [32], [34]. For practical and structural reasons, the lower value of 0.2 has been chosen, since it results in a larger chord near wing root, which is needed for engines placement, as well as because it creates enough internal volume due to increased maximum thickness, making it possible to house the landing gear and fuel tanks. The aircraft will have a zero dihedral and a lowwing configuration mainly for the practical reason of placing the landing gear. A summary of the basic wing dimensions is presented at the Table 4 below.

Table 4. Summary of wing basic dimensions.

\begin{tabular}{cc}
\hline Parameter (unit) & Value \\
\hline Area $\left(\mathrm{m}^{2}\right)$ & 63.75 \\
Span $(\mathrm{m})$ & 14.28 \\
Root chord (m) & 7.44 \\
Tip chord (m) & 1.49 \\
Mean Aerodynamic Chord-MAC (m) & 5.12 \\
Spanwise location of the MAC (m) & 2.78 \\
\hline
\end{tabular}


The horizontal and vertical tail area are estimated using the tail volume coefficients, which relate the wing to the tail size. An initial estimation for the vertical tail can be made using the equation (3) (from [32]):

$S_{V T}=\frac{V_{V T} b_{W} S_{W}}{L_{V T}}$

in which $\mathrm{S}_{\mathrm{v}}$ is the vertical tail surface, $\mathrm{V}_{\mathrm{v}}$ is the volume coefficient, $b_{w}$ is the wingspan, $\mathrm{S}_{\mathrm{w}}$ is the wing surface and $\mathrm{LvT}_{\mathrm{T}}$ is the moment arm of the vertical tail. Decreasing the horizontal tail volume is critical in order to achieve an area-ruled design and decrease the wave drag. The tail arm moment $L$, which is initially approximated as the longitudinal distance of the quarter position of the wing mean chord to the quarter mean chord position of the tail, has been set to $40 \%$ of the fuselage length for both the vertical and horizontal tail arm. The horizontal stabilizer has been modelled as a straight trailing edge tapered wing, with a leading edge sweep angle of 50 degrees, which is typically 5 degrees larger than the wing sweep, so that it experiences a greater critical Mach number compared to the wing.

The vertical stabilizer has been modelled as a trapezoidal wing having a 60 degrees leading edge sweep angle. The selected values for the AR are 2.5 for the horizontal and 1.3 for the vertical stabilizer, while the taper ratio is 0.15 and 0.2 for the horizontal and the vertical stabilizer respectively. The NACA 64-006 aerofoil has been selected for the horizontal stabilizer and the symmetric NACA 64-009 has been selected for the vertical stabilizer. A summary of the basic tail dimensions is presented at the Table 5 below.

Table 5. Summary of tail basic dimensions.

\begin{tabular}{ccc}
\hline Parameter (unit) & $\begin{array}{c}\text { Horizontal stabilizer } \\
\text { value }\end{array}$ & $\begin{array}{c}\text { Vertical stabilizer } \\
\text { value }\end{array}$ \\
\hline Area $\left(\mathrm{m}^{2}\right)$ & 12.10 & 7.59 \\
Span $(\mathrm{m})$ & 5.50 & 3.14 \\
Root chord $(\mathrm{m})$ & 3.84 & 4.03 \\
Tip chord $(\mathrm{m})$ & 0.56 & 0.81 \\
Mean Aerodynamic & 2.61 & 2.77 \\
Chord-MAC $(\mathrm{m})$ & & \\
\hline
\end{tabular}

\subsubsection{Fuselage}

The fuselage has been dimensionalised taking two important factors into consideration. First, the existence of enough usable volume to host the passengers and secondly, the area rule design requirements [35]. Applying the area rule dictates that the fuselage has to be squeezed at the area where the wing is placed, so that a smooth volume distribution and a smaller cross-sectional area is achieved. An initial estimation for the fuselage length (Lus) for a jet transport is provided using the relation of the equation (4), which is based on statistical data [32].

$$
L_{f u s}=0.287 W_{0}^{0.43}
$$


in which $W_{0}$ is the takeoff weight. The length of the fuselage has then been enlarged by about $3 \mathrm{~m}$ compared to the initial estimation above. This was done mainly for two reasons. While the fuselage maximum diameter is enough to host two passengers sitting side-by-side, for the portion of fuselage that is squeezed, this would not be possible and just one passenger could be hosted there. The need to place also a lavatory increases the compartment's length requirements.

Additionally, the typical cabin compartment to overall length ratio for a supersonic transport is about 0.55 [34], thus the lengthened fuselage should provide enough space for hosting all the 15 passengers. Finally, the supersonic aircraft has a sharper and longer nose in comparison to the subsonic aircraft, and a typical value of its nose length to diameter ratio is about 4 [32]. This is to avoid strong bow shock waves forming at the fuselage nose, which lead to a significant increment of the wave drag. However, having a very low nose length to diameter ratio would create practical problems with the cockpit housing and the unhindered pilots' visibility, especially during landing. Figure 1 shows the fuselage's top view and Figure 2 shows the fuselage's side view.

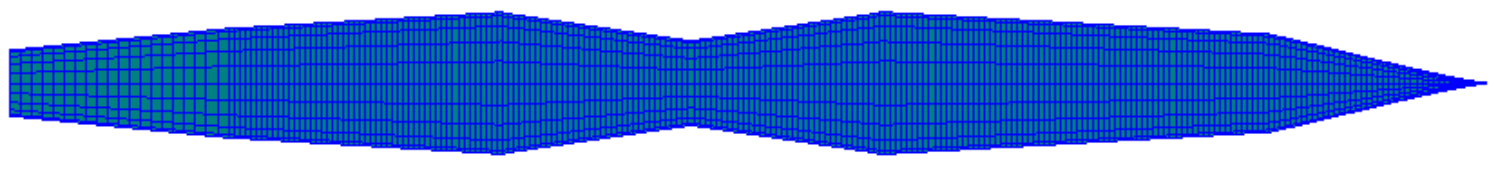

Figure 1. Fuselage top view

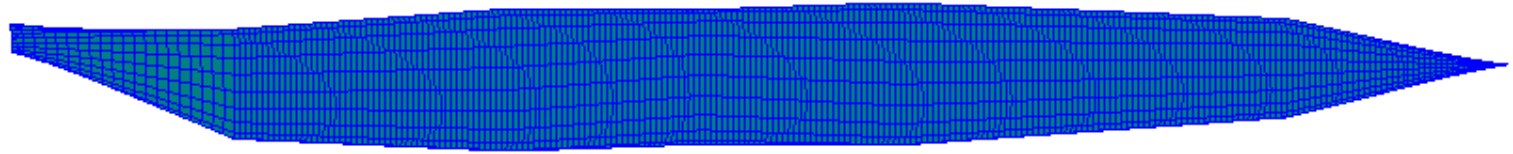

Figure 2. Fuselage side view

As it can be seen at Figure 2, the tail fuselage is converging towards the higher side, so that the empennage can be placed higher up of the wing and thus minimize the aerodynamic interactions due to the wing wake. The basic dimensions of the fuselage lofting are presented in Table 6 . The fuselage total volume has been calculated to be $78.75 \mathrm{~m}^{3}$.

Table 6. Summary of fuselage basic dimensions.

\begin{tabular}{cc}
\hline Parameter (unit) & Value \\
\hline Nose length $(\mathrm{m})$ & 4.00 \\
Nose maximum diameter $(\mathrm{m})$ & 1.80 \\
Cylindrical part length $(\mathrm{m})$ & 19.00 \\
Cylindrical part maximum diameter $(\mathrm{m})$ & 2.60 \\
'Squeezed' part minimum width $(\mathrm{m})$ & 1.56 \\
Fuselage tail length $(\mathrm{m})$ & 4.00 \\
Fuselage tail maximum diameter $(\mathrm{m})$ & 2.00 \\
\hline
\end{tabular}


A low-wing configuration has been chosen for this aircraft design. The position of the quarter MAC has been placed in the longitudinal direction $14.07 \mathrm{~m}$ behind the fuselage nose. The area ruled, fuselage-wing assembly can be seen in Figures 3 and 4.

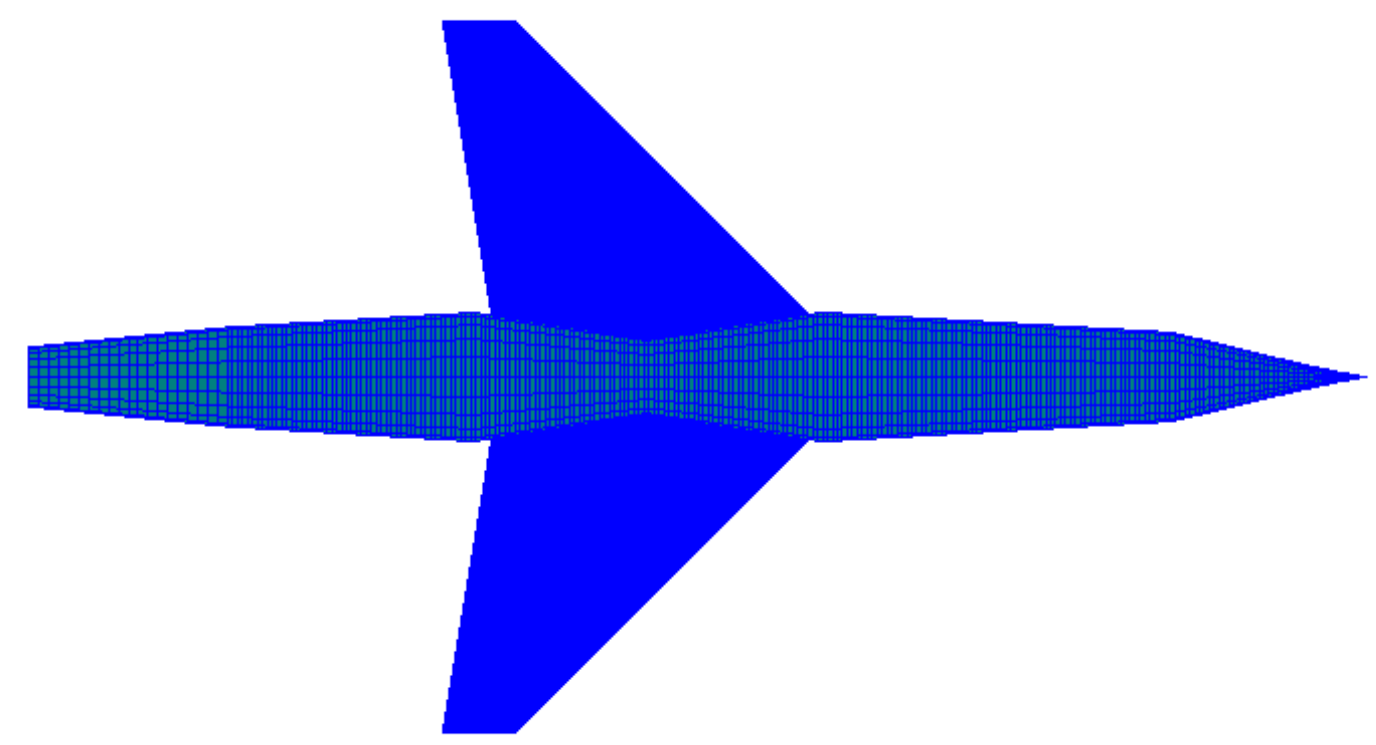

Figure 3. Fuselage-wing assembly top view

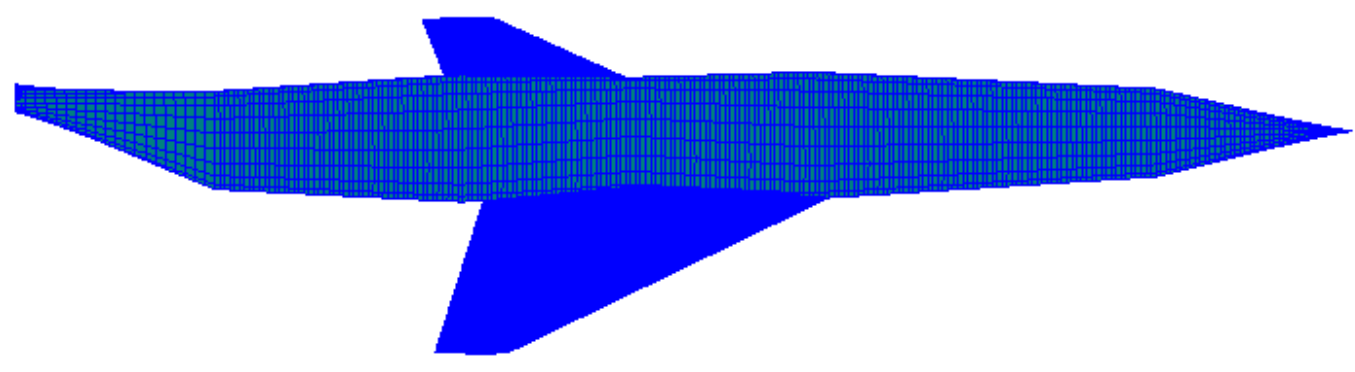

Figure 4. Fuselage-wing assembly side view

This configuration favors a long enough tail arm moment, which results in a smaller tail size and demands the placement of the wing forward. However, the placement of the wing too much forward, will have the side effect of a much longer and heavier landing gear and perhaps a higher than usual load acting on the nose landing gear.

\subsubsection{Air intake}

For the propulsion system, a similar concept to Concorde is followed, with each engine mounted at the lower side of the wing. For supersonic fighter jets the most common configuration is to use fuselage side-mounted inlets. This arrangement provides short ducts and relatively clean, 
undistorted air. However, this is not possible for the low-wing configuration passenger aircraft for practical reasons, for instance due to the need of placing the engines outside the fuselage and the need of landing gear stowage. Using a configuration like the Concorde, has the advantages of having a quite undisturbed airflow, of avoiding interferences between the two exhaust nozzles and of decreasing the structural stress on the wing, due to the inertial relief effect. Achieving proper operation for the compressor blades means that the airflow has to be decelerated to about 0.4 Mach [36]. The efficiency of the intake is disproportionately related to the total pressure loss, and the total pressure loss is mainly dependent to the shock-wave pattern. The air intakes used for supersonic flight consist of two parts: the converging supersonic inlet and the diverging subsonic diffuser.

The type of supersonic inlet that has been used for the SSBJ design is the external compression rectangular ramp inlet, where the weak oblique shocks are generated outside the inlet and are followed by a normal shock at the cowl lip. In order to achieve very high efficiency, the shock pattern consists of three weak oblique shocks before the normal shock. Table 7 presents the wedge angles and the results of the four-shock external compression inlet design.

Table 7. Properties of the 4-shock external inlet (Free stream Mach number: 1.7).

\begin{tabular}{cccc}
\hline Wedge angle (deg) & Mach number & Shock angle (deg) & Pressure recovery (\%) \\
\hline 5.9 & 1.59 & 39 & 99.96 \\
5.8 & 1.49 & 42 & 99.96 \\
6.1 & 1.27 & 50 & 99.71 \\
- & 0.80 & 90 & 98.40
\end{tabular}

The total pressure recovery for the designed supersonic inlet reaches $98.40 \%$ for decelerating the airflow from 1.7 to about 0.8 Mach. During off-design operation, the mass flow demand at lower speeds is reduced. This reduction in the demand results in the static pressure rising at the compressor inlet, which forces the flow to spill outside the compressor. Since this redundant subsonic flow has to spill out, the normal shock moves further upstream from the lip cowl, increasing the so-called spillage drag significantly [37]. In order to avoid this effect and keep the normal shock attached at the cowl lip, a by-pass door is used in the diffuser, so that the excess air can be by-passed before reaching the compressor.

\subsubsection{Propulsion system}

The main criteria for the engine selection are to provide enough thrust for the aircraft operation, satisfying the maximum thrust-to-weight ratio, to have a low thrust specific consumption and a low weight and a small size, to minimize the parasite drag. To satisfy the fuel consumption requirement, it is preferable to incorporate a low-bypass ratio afterburning turbofan instead of a turbojet. Another benefit of the turbofan engine is the reduced noise. Out of the existing engines which should satisfy the criteria, the turbofan EJ200 has been selected and its specifications are shown in Table 8 [38]. Two EJ200 engines have been used in the proposed design.

Table 8. Propulsion system basic dimensions (from [38]). 


\begin{tabular}{cc}
\hline Parameter (unit) & Value \\
\hline Intake length $(\mathrm{m})$ & 2.36 \\
Capture area $\left(\mathrm{m}^{2}\right)$ & 0.416 \\
Throat diameter $(\mathrm{m})$ & 0.60 \\
Nacelle length $(\mathrm{m})$ & 5.36 \\
Nacelle width $(\mathrm{m})$ & 0.78 \\
\end{tabular}

The dimensions of the intake and thus of the whole propulsion system can now be quantitatively determined. The respective ratio of intake length to engine diameter is about 3.19. The two nacelles have been placed in distance $2.9 \mathrm{~m}$ from the aircraft longitudinal axis of symmetry. Table 9 shows the specifications of the EJ200 engine.

Table 9. EJ200 engine specifications (from [38]).

\begin{tabular}{cl}
\hline Parameter (unit) & Value \\
\hline Maximum thrust, dry (KN) & 60.0 \\
By pass ratio & 0.40 \\
Overall pressure ratio & $26: 1$ \\
Specific fuel consumption, dry (g/KNs) & 21.0 \\
Air flow rate (Kg/s) & 77.0 \\
Maximum diameter (m) & 0.74 \\
Length $(\mathrm{m})$ & 4.00 \\
Weight $(\mathrm{Kg})$ & 1010 \\
\hline
\end{tabular}

The aircraft model top and side views are shown at the Figures 5 and 6 respectively.

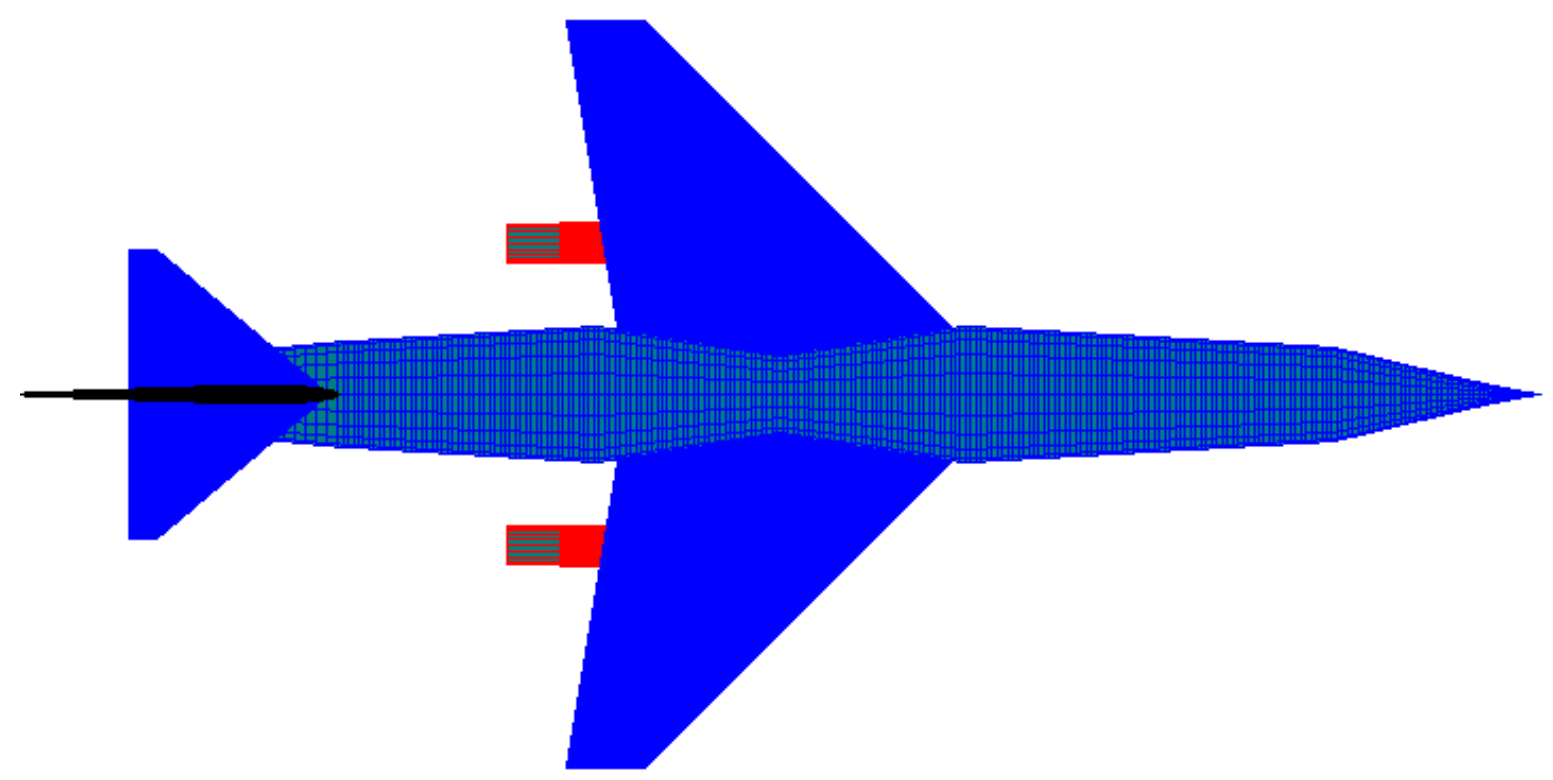

Figure 5. Aircraft model top view 


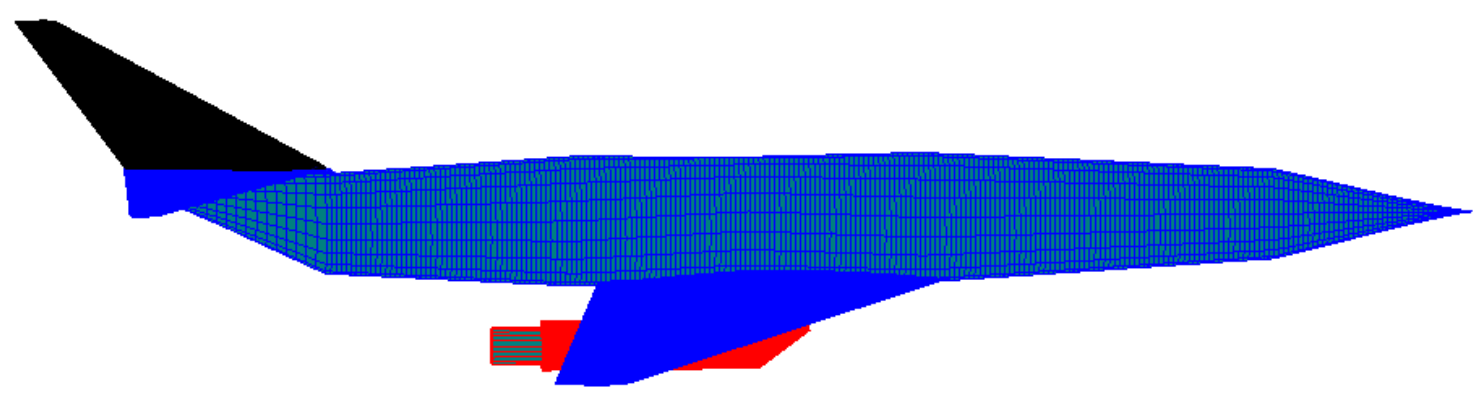

Figure 6. Aircraft side view

\section{Environmental Impact Assessment Results and Discussion}

\section{1. $\mathrm{CO}_{2}$ and $\mathrm{H}_{2} \mathrm{O}$ emissions}

The emissions of $\mathrm{CO}_{2}$ and $\mathrm{H}_{2} \mathrm{O}$ have been calculated by using the method outlined at [29]. Tables 10 and 11 show how the calculated emissions of $\mathrm{CO}_{2}$ and $\mathrm{H}_{2} \mathrm{O}$ of the SSBJ design compare to those of a commercial subsonic airliner. The results correspond to a transatlantic flight of $6050 \mathrm{~km}$ with a $100 \%$ passenger load factor. The emissions of the SSBJ design per $\mathrm{Km}$ are lower, which is explained by its lower payload (just 15 passengers instead of the 416 of the Boeing 747) and thus smaller size. However, the emissions of $\mathrm{CO}_{2}$ and $\mathrm{H}_{2} \mathrm{O}$ per $\mathrm{Km}$ per seat of the SSBJ are about 5.85 times greater than the subsonic airliner. That is explained by the fact that the SSBJ cruises at a significantly smaller liftto-drag ratio and with a larger thrust specific fuel consumption. In particular, the specific fuel consumption of the RB211-524H installed in Boeing 747 during cruise is $16.14 \mathrm{~g} / \mathrm{KN} / \mathrm{s}$ [39], which is a considerably lower value.

Table 10. Water vapor emissions comparison (6050 Km distance flown).

\begin{tabular}{ccc}
\hline Aircraft & $\mathbf{H}_{2} \mathbf{O}(\mathbf{K g} / \mathbf{K m})$ & $\mathbf{H}_{2} \mathbf{O}(\mathbf{K g} / \mathbf{K m} /$ seat $)$ \\
\hline Boeing 747 & 13.22 & 0.032 \\
SSBJ & 2.79 & 0.186 \\
& & \\
\hline
\end{tabular}

Table 11. Carbon dioxide emissions comparison (6050 Km distance flown).

\begin{tabular}{ccc}
\hline Aircraft & $\mathrm{CO}_{2}(\mathrm{Kg} / \mathrm{Km})$ & $\mathrm{CO}_{2}(\mathrm{Kg} / \mathrm{Km} /$ seat $)$ \\
\hline Boeing 747 & 33.70 & 0.081 \\
SSBJ & 7.12 & 0.47 \\
& & \\
\hline
\end{tabular}

From the obtained results, it can be inferred that the influence of small supersonic aircraft flight would not be so environmentally problematic concerning the greenhouse effect. However, an excessive growth of the supersonic transportation, especially in the case of large supersonic transports replacing part of the current subsonic fleet, could essentially affect the total aviation 
emissions. Moreover, the phenomenon of the persistent contrails and cirrus clouds formation at the stratosphere and its consequences on the environment would need to be further investigated.

\subsection{Ozone layer depletion}

The influence of the supersonic flight on the ozone layer constitutes a serious environmental concern. Nearly $90 \%$ of the ozone exists in the stratosphere, forming the ozone layer. Since the SSBJ cruises at high altitudes from 48,000 to about $57,000 \mathrm{ft}$, the aircraft will directly emit the produced NOx in the stratosphere and thus in the ozone layer. The subsonic airliners executing long haul flights at a cruise altitude of around 35,000 ft are emitting NOx in the low level of the stratosphere as well. The NOx in the stratosphere are participating in a catalytic chemical reaction, which leads to the ozone destruction. The ozone layer breakdown could allow the ultraviolet $\mathrm{B}$ radiation from the sun to pass through this ozone shield and reach the Earth, which could cause among else skin cancer and cataract in humans and could potentially harm the animals as well. Both the subsonic and supersonic aircraft emit NOx in the stratosphere, however, the impact of the SSBJ flying at higher flight altitudes is more significant due to the increased ozone concentration. The highest ozone concentrations are observed between 60,000 and $80,000 \mathrm{ft}$, which comprise the typical flight altitudes of supersonic aircraft at speeds equal to Mach 2 and higher [8]. Thus, relatively long flights of large supersonic transports with speeds greater than Mach 2, cruising at altitudes near the maximum ozone concentration while burning big amount of fuel, could potentially be the most problematic supersonic passenger jet concept regarding the ozone depletion environmental impact.

The NOx are produced during the combustion of the kerosene. Work by Lipfert [40] has shown a simple correlation between the NOx emission index (EINOx) and the combustor inlet total temperature ( $\left.T_{t c}\right)$. The equation (5), found on [29], is an empirical relation for the prediction of the NOx emissions based on the so-called Lipfert correlation:

$$
E I_{N O x}=10^{\left(1+0.0032\left(T_{t c}-581.25\right)\right)} \sqrt{\delta}
$$

in which $\delta$ is the ratio of the static pressure at the cruise altitude to the sea level static pressure. The equation (5) demonstrates that for high combustor inlet temperatures, thus for high engine pressure ratios, the NOx emissions of the engine are significantly increased. The pressure ratio, determining the total temperature at the compressor exit, influences the actual primary zone temperature in the combustion chamber [29] hence, the NOx production as well. The NOx production is also affected by the equivalence ratio $\Phi$, which is used to indicate quantitatively whether a fuel-air mixture is lean, stoichiometric, or rich:

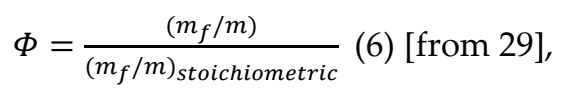

in which $\mathrm{m} f$ is the fuel mass and $\mathrm{m}$ is the air mass.

In Figure 7, the variation of the calculated NOx emissions index is presented with respect to the overall pressure ratio for a subsonic airliner and for the SSBJ design. The example of the subsonic aircraft that was used is the Boeing 747-400, and the relevant cruise conditions are 0.85 Mach at a flight altitude of $11 \mathrm{~km}$. For the SSBJ the cruise speed is 1.7 Mach at an average flight altitude of $16 \mathrm{~km}$. The upper limit of the overall pressure ratio, including the fan, of the RB211-524H engine of the 
Boeing 747-400 is set to 33 [39], while for the EJ200 is set to 22, so that the total temperature at the compressor exit does not exceed $900 \mathrm{~K}$, which is a practical limit of the compressor materials and its cooling requirements [41].

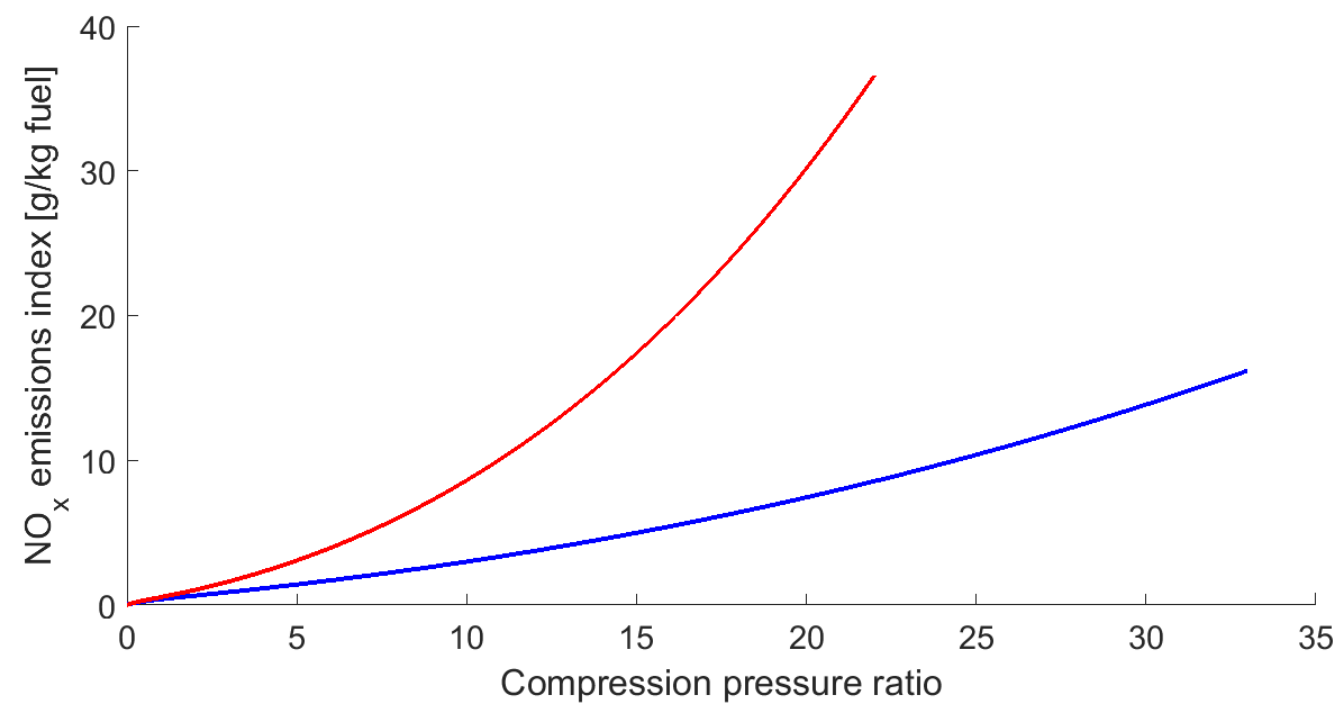

Figure 7. NOx emissions index for the SSBJ design (red) and for a typical long haul subsonic airline (blue).

For the RB211-524H engine, a diffuser isentropic efficiency of 0.97 has been assumed, while the intake isentropic efficiency for the SSBJ has been estimated at 0.95 . For both engines, the compression isentropic efficiency has been set to the typical value of 0.85 . From the calculated values illustrated on Figure 5, the maximum EINOx of the subsonic aircraft is about $16.2 \mathrm{~g} / \mathrm{kg}$ fuel at its maximum compression ratio of 33 , which is a value that agrees with the relevant ones stated at the study of Wahner and Geller [42]. On the contrary, the pressure ratio effect on the EINOx of the SSBJ is much more prominent with an emissions index of $36.58 \mathrm{~g} / \mathrm{kg}$ fuel at the maximum set pressure ratio of 22 . The increased fuel consumption of the SSBJ is also a parameter that contributes to even higher NOx emissions, generating concerns about the environmental viability of an excessive turn in supersonic transportation in the near future.

\section{Conclusions}

Research suggests that the climate effects due to non- $\mathrm{CO}_{2}$ emissions from supersonic aircraft could be considerably greater than the non- $\mathrm{CO}_{2}$ effects from subsonic aircraft [43]. Furthermore, no noise neither $\mathrm{CO}_{2}$ certification requirements exist for supersonic aircraft in Europe [44], while the FAA has recently initiated steps for noise certification and special flight authorization for conducting supersonic flight testing in the USA [45]. In order to keep NOx emissions within acceptable limits, an emissions index as low as 5 during cruise, which corresponds to about a $80 \%$ reduction of the above calculated values, would be necessary. In order to achieve such low NOx emissions, new engine concepts have to be developed emphasizing on this reduction, while maintaining the other engine requirements of low thrust specific fuel consumption, high thrust-to-weight ratio and reliability. Novel nozzle integration techniques can be investigated for that purpose [46]. Moreover, the 
economic viability of the undertaking to build a new engine capable to be incorporated at supersonic aircraft has to be examined as well. In order to reduce the NOx emissions, the equivalence ratio $\Phi$ has to be controlled, so that the engine operates in the low emissions region of $\Phi$. Moreover, it is important to reduce the time of the gases remaining in high temperatures. There are different types of combustor concepts, referred to as dry low NOx combustors, which focus on more efficient, as regards the relevant emissions, combustion process. Finally, the water emissions in the stratosphere is believed to have some influence on the ozone destruction too, since it can affect the composition, growth and aerosol reactions and provide a source of HOx radicals that enhance ozone loss [8]. However, this is an effect that should be further investigated, so that the effect of the water vapor emissions in the ozone layer becomes more certain.

Author Contributions: The authors contributed equally to the preparation of the article.

Funding: This research received no external funding.

Conflicts of Interest: The authors declare no conflicts of interest.

\section{References}

1. Boom Technology Official Web site. Available online: https://boomsupersonic.com/ (accessed on 28 October 2019)

2. Liebhardt, B., Lutjens, K. An analysis of the market environment for supersonic business jets; German Aerospace Center (DLR)-Air Transportation Systems, Hamburg, Germany, 2011.

3. Airbus Global Market Forecast Mapping Demand 2016-2035. Available online: https://www.airbus.com/content/dam/corporate-topics/financial-and-companyinformation/GMF.pdf (accessed on 28 October 2019)

4. Liebhardt, B., Lutjens, K., Gollnick, V. Estimation of the market potential for supersonic airliners via analysis of the global premium ticket market. In proceedings of: $11^{\text {th }}$ AIAA Aviation Technology, Integration and Operations Conference, Virginia Beach, VA, USA, 2011 (AIAA 2011-6806)

5. Sun, Y., Smith, H. Review and prospect of supersonic business jet design. Progress in Aerospace Sciences.2017, 90, 12-38.

6. Henne, P.A. Case for small supersonic civil aircraft. Journal of Aircraft.2005, 42 (3), 765-774.

7. Li, W. Feasibility of supersonic aircraft concepts for low-boom and flight trim constraints. In proceedings of: 33 ${ }^{\text {rd }}$ AIAA Applied Aerodynamics Conference, Dallas, TX, USA, 2015 (AIAA 2015-25810).

8. National Academy Press. Commercial Supersonic Technology: The Way Ahead. Washington DC, USA, 2001.

9. Alkaya, C., Sam, A.A., Pesyridis, A. Conceptual advanced transport aircraft design configuration for sustained hypersonic flight. Aerospace. 2018, 5, 91.

10. Welge, H., Nelson, C. and Bonet, J. Supersonic vehicle systems for the 2020-2035 timeframe. In proceedings of: $28^{\text {th }}$ AIAA Applied Aerodynamics Conference, Chicago, Illinois, USA, 2010 (AIAA 2010-4930). 
11. Carreras, C., Daouk, M., Dowen, T., Jamonet, L., Lederle, S., Sharman, D. and Wertenberg, $R$. The case for a practical small supersonic transport. In proceedings of: $23^{\text {rd }}$ International Congress of Aeronautical Sciences, Toronto, Canada, 2002.

12. Dahlmann, K., Koch, A., Linke, F., Luhrs, B., Grewe, V., Otten, T., Seider, D., Gollnick, V., Schumann, U. Climate-compatible air transport system-Climate impact mitigation potential for actual and future aircraft. Aerospace. 2018, 5, 60.

13. Noppel, F., Singh, R. Contrail avoidance in the aircraft design process. Aeronautical Journal. 2008, 112, 733-737

14. Filippone, A. Cruise altitude flexibility of jet transport aircraft. Aerospace Science and Technology. 2010, 14, 283-294

15. Schwartz Dallara, E., Kroo, I., Waitz, I. Metric for comparing lifetime average climate impact of aircraft. AIAA Journal. 2011, 49, 1600-1613

16. Zapryagaev, V., Kiselev, N., Gubanov, D. Shock-wave structure of supersonic jet flows. Aerospace. 2018, 5, 60.

17. Whitham, G.B. The flow pattern of a supersonic projectile. Communications on Pure and Applied Mathematics. 1952, 5, 301-348.

18. Whitham, G.B. On the propagation of weak shock waves. Journal of Fluid Mechanics. 1956, 1, 290-318

19. Darden, C. M. Progress in sonic boom understanding: Lessons learned and next steps. In proceedings of: High Speed Research: 1994 Sonic Boom Workshop Conference, Hampton, Virginia, 1994, USA.

20. Haglund, C. M. Low sonic boom design activities at Boeing. In proceedings of: High Speed Research: 1994 Sonic Boom Workshop Conference, Hampton, Virginia, 1994, USA.

21. Cheung, S. H., Edwards, T. A. Supersonic airplane design optimisation method for aerodynamic performance and low sonic boom; NASA Ames Research Center, Moffet Field, USA, 1992.

22. Rallabhandi, S.K., Mavris, D.N. Sonic boom minimization using inverse design and probabilistic acoustic propagation. Journal of Aircraft.2006, 43 (6), 1815-1828.

23. Mack, R. J. A supersonic business jet concept designed for low sonic boom. NASA Langley Research Center, Hampton, Virginia, 2004, USA.

24. Bobbit, P. J. Application of Computational Fluid Dynamics and laminar flow technology for improved performance and sonic boom reduction. Eagle Engineering, Hampton Division, 1992, USA.

25. Shepherd, K. P. and Sullivan, B.M. A loudness calculation procedure applied to shaped sonic booms. NASA Langley Research Center, Hampton, Virginia, 1991, USA.

26. Carlson, H. W., Barger, R. L., Mack, R.J. Application of sonic boom minimization concepts in supersonic transport design. NASA Langely Research Center, Hampton, Virginia, 1973, USA

27. Jardine, C. N. Calculating the environmental impact of aviation emissions; Environmental Change Institute, Oxford, United Kingdom, 2005

28. European Environment Agency. European Aviation Environmental Report 2016. Available online:https://ec.europa.eu/transport/sites/transport/files/european-aviation-environmentalreport-2016-72dpi.pdf (accessed on 28 October 2019) 
29. Ruijgrok, G.J.J., van Paasen, D.M. Elements of Aircraft Pollution; Delft University Press, Delft, The Netherlands, 2007; ISBN 978-90-407-2602-6

30. Mariens, J.; Elham, A.; van Tooren, M.J.L. Influence of weight modelling on the outcome of wing design using multidisciplinary design optimisation techniques. Aeronautical Journal, 2013, 117, 871-895.

31. Roskam, J. Airplane Design: component weight estimation (Part V); DAR Corporation, 1999; ISBN 9781884885501

32. Raymer, D.P. Aircraft Design: A Conceptual Approach; $5^{\text {th }}$ edition, AIAA Education Series, Washington DC,USA, 2012; ISBN 978-1-60086-911-2

33. Torenbeek, E. Advanced Aircraft Design, Conceptual Design, Analysis and Optimisation of Subsonic Civil Airplanes. John Wiley and Sons Ltd, West Sussex, UK, 2013, p.410

34. Howe, D. Aircraft Conceptual Design Synthesis; Wiley, London, UK, 2005; ISBN 978-1860583018

35. Whitcomb, R.T., Sevier, J.R. A supersonic area rule and an application to the design of a wing-body combination with high lift-drag ratios. Technical report R-72, NASA, Langley Research Center, Hampton, Virginia, 1960, USA.

36. Ran, H., Mavris, D. Preliminary design of a 2D supersonic inlet to maximise total pressure recovery. In proceedings of: $5^{\text {th }}$ AIAA Aviation, Technology, Integration and Operations (ATIO) Conference, Arlington, Virginia, USA, 2005 (AIAA 2005-7357).

37. Williams, M. J., Stevens, K. A. Computational prediction of subsonic intake spillage drag. In proceedings of: $24^{\text {th }}$ AIAA Applied Aerodynamics Conference, San Francisco, California, USA, 2006 (AIAA 2006-3871).

38. MTU Aero Engines Official Web site. Available online:

https://www.mtu.de/fileadmin/EN/7 News Media/2 Media/Brochures/Engines/EJ200.pdf (accessed on 28 October 2019)

39. Jenkinson, L.R., Simpkin, P., Rhodes, D. Civil Jet Aircraft Design, AIAA Education Series, Washington DC,USA, 1999; ISBN 978-0340741528.

40. Lipfert, F. W. Correlation of gas turbine emissions data. In proceedings of: Gas Turbine and Fluids Engineering Conference, San Francisco, California, 1972, USA

41. Farokhi, S. Aircraft Propulsion, Wiley, London, United Kingdom, 2009; ISBN 978-0470039069.

42. Wahner, A., Geller, M.A. Scientific assessment of ozone depletion: Subsonic and supersonic aircraft emissions; National Oceanic and Atmospheric Administration, Maryland, USA, 1994.

43. Grewe, V., Plohr, M., Cerino, G., Di Muzio, M., Deremaux, Y., Galerneau, M., de Saint Martin, P., Chaika, T., Hasselrot, A., Tengzelius, U., Korovkin, V.D. Estimates of the climate impact of future small scale supersonic transport aircraft-Results from the HISAC EU project. Aeronautical Journal. 2010, 114, 1153.

44. EASA Official Web site. Available online: https://www.easa.europa.eu/eaer/topics/technology-and-design/supersonic-aircraft (accessed on 28 October 2019)

45. FAA Official Web site. Available online: Web site. Available online: https://www.faa.gov/news/fact sheets/news story.cfm?newsId=22754 (accessed on 28 October 2019)

46. Takahashi, H., Munakata, T., Sato, S. Thrust augmentation by airframe-integrated linearspike nozzle concept for high-speed aircraft. Aerospace. 2018, 5, 19. 